\title{
ORALITURA E A FIGURA MITOLÓGICA DE IYÁ MI OXORONGÁ EM “CAROÇO DE DENDÊ”, DE MÃE BEATA DE YEMONJÁ
}

\author{
Oralitura and the mythological figure of lyá Mi Oxorongá in "Caroço de dendê", by \\ Mãe Beata de Yemonjá
}

\author{
Dênis Moura de Quadros \\ https://orcid.org/0000-0001-5733-6857 (0) \\ Universidade Federal do Rio Grande, Programa de Pós-Graduação em Letras, Rio Grande, RS, \\ Brasil.96203-900 - ppgletras@furg.br
}

\begin{abstract}
Resumo: Caroço de Dendê: a sabedoria dos terreiros: como lalorixás e Babalorixás passam conhecimento a seus filhos (2008), cuja primeira edição data de 1997, de Mãe Beata de Yemonjá (1931-2017), é composto por 43 contos que mesclam ítãs (lendas dos Orixás) e outras estórias de terreiro, destes escolhemos três "O cachimbo de Tia Cilu"; "Iyá Mi, a mãe Ancestral" e "Conto dedicado a minha mãe, Do Carmo" que resgatam a ancestralidade das Mães feiticeiras, as lyá Mi Oxorongás, figuras mítico-religiosas da cultura afro-brasileira. O arcabouço teórico é composto pelo conceito de Leda Martins (1997; 2003; 2007) "oralitura" bem como os estudos de Heloisa Toller Gomes (2004; 2007), Conceição Evaristo (2011) e Ana Rita Santiago (2012) ao que tange o conceito de literatura afrofeminina, uma literatura atravessada pela condição de mulher e negra e tudo a que isso implica. As iyá-mis Oxorongás são a representação e manutenção da cultura matriarcal africana e afrodiaspórica, ancestrais ímpares nas religiões de matriz africana.
\end{abstract}

Palavras-chave: Oralitura. Literatura afroeminina. Mitologia afro-brasileira.

Abstract: Caroço de Dendê: a sabedoria dos terreiros: como lalorixás e Babalorixás passam conhecimento a seus filhos (2008), whose first edition dates from 1997, of Mãe Beata de Yemonjá (1931-2017), is composed of 43 tales that merge the lthans (legends of the Orixás) and other stories of Terreiro, of these we choose three: três "O cachimbo de Tia Cilu"; "Iyá Mi, a mãe Ancestral" and "Conto dedicado a minha mãe, Do Carmo", that rescue the ancestry of the sorcerers' mothers, the lyá Mi Oxorongás, mythic-religious figures of the afro culture. The theoretical framework is composed of the concept of Leda Martins $(1997 ; 2003 ; 2007)$ "Oralitura" as well as the studies by Heloisa Toller Gomes (2004; 2007), Conceição Evaristo (2011) and Ana Rita Santiago (2012) to the concept of afrofeminine literature, a literature crossed by the condition of woman and black and all that implies. The lyá-mis Oxorongás are the representation and maintenance of african matriarchal and afrodiaspathic culture, unique ancestors in the religions of African matrix.

Keywords: Oralitura. Afrofeminine Literature. Afro-brazilian mythology.

Mãe Beata de Yemonjá (1931-2017), identidade afrofeminina de Beatriz Moreira Costa, é uma das mais importantes figuras na cultura afro-brasileira, corro o risco de afirmar que Mãe Beata seja a primeira Yalorixá a escrever um livro de contos que mesclam os ítans (lendas dos Orixás) a elementos brasileiros e contemporâneos. Ao lado de Mãe Stella de 
Oxóssi (1925-2019), a figura de Mãe Beata marca a resistência negra e a consciência política das mulheres negras que estão à frente de importantes quilombos afro-brasileiros: os terreiros. Ambas pertencem ao Candomblé, mas não podemos esquecer que as religiões de matriz africana se desenvolvem em outras regiões com outras nomenclaturas e fundamentos religiosos afins como, por exemplo, o Batuque no Rio Grande do Sul.

Pesquisando as dissertações e teses defendidas que trazem como corpus, em especial, a obra $O$ caroço de dendê: a sabedoria dos terreiros: como ialorixás e babalorixás passam conhecimento a seus filhos (2008), encontramos três trabalhos: duas dissertações e uma tese. O primeiro trabalho é a dissertação Os "fios de Contos" de mãe Beata de Yemonjá: mitologia afro-brasileira e educação (UERJ) de Glória Cecília de Souza Silva (2008), que trama a presença dos ítans "em movimento", ou seja, aplicados ao cotidiano dos leitores/alunos. O segundo trabalho é a dissertação Tempos de griotizar a letra: em busca de uma poética da voz afro-brasileira em Caroço de dendê, de Mãe Beata de Yemonjá (UEL) de Juliana Franco Alves (2012), em que a autora analisa a obra beatiana pela perspectiva africana da figura do griot, nessa análise ela, seguindo Exu, "entrecruza" três vias: a oralidade, a escrita e o Candomblé. Por fim, o trabalho mais recente é a tese De Stamps ao Recôncavo: encruzilhada de narrativas afrodescendentes traduzidas em literatura contemporânea (UERJ) de Felipe Fanuel Xavier Rodrigues (2016), em sua tese Felipe analisa a obra de Maya Angelou (1928-2014) e a obra de Mãe Beata fazendo uma leitura crítica dos contextos. Apesar de compreender e analisar sob o viés da ancestralidade, a tese atinge, sobretudo, a contemporaneidade dos textos, percebendo como as imagens, mitos e tradições se desenvolvem nas narrativas de Maya Angelou e Mãe Beata de Yemonjá.

Os três trabalhos abordam, de diferentes perspectivas, a relação da oralidade nos contos de Mãe Beata de Yemonjá, sendo assim, a base teórica recorrente dos três trabalhos é composta pelo crítico literário Paul Zumthor (1915-1995), especificamente sua obra $A$ letra e a voz publicada em 1989 e traduzido para o Brasil em 1993. Assim, buscando afrocentrar não apenas a literatura como, também, a crítica literária, elenco o termo de oralitura da pesquisadora negra Leda Martins $(1997 ; 2003 ; 2007)$ e o conceito de literatura afrofeminina da pesquisadora negra Ana Rita Santiago (2012). Afinal, oralidade não é nenhuma novidade para a cultura afro-brasileira, base da cultura desde África e preservada na diáspora negra.

A análise da obra de Mãe Beata de Yemonjá, que também publica Histórias que minha avó contava (2004), contempla, neste trabalho, o recorte de três contos que trazem a (auto) representação das mulheres negras, em especial, sob a figura mítica-religiosa das lyá Mi Oxongás, as mães feiticeiras que viram pássaros. Os contos são: "O cachimbo de Tia Cilu"; "Iyá Mi, a mãe Ancestral" e "Conto dedicado a minha mãe, Do Carmo". No primeiro conto a presença da Tia Cilú em seu Axexé (ritual mortuário), representando que todo iniciado no Candomblé não morre ou mesmo deixa de existir de forma coletiva, mas torna-se Ancestral. Já o segundo, "Iyá Mi, a mãe Ancestral", evoca o ítan das mães feiticeiras, temidas pelo 
seu poder e, sobretudo, seu poder feminino de dar vida e de tirá-la. O último, "Conto dedicado a minha mãe, Do Carmo", conta a história do nascimento da própria Mãe Beata, nascida em uma encruzilhada após a pescaria de sua mãe, filha de Yemonjá e Esú.

Conceição Evaristo é a responsável por escrever o verbete de Mãe Beata de Yemonjá na antologia crítica Literatura e afrodescendência no Brasil (2011), organizada por Eduardo de Assis Duarte. No verbete, Evaristo (2011) analisa a forte presença da oralidade nos contos de mãe Beata, advindos da ancestralidade afro-brasileira, mesclando histórias e memórias e afirma que: "ao recuperar essas reminiscências, dá a elas o status de escrita." (EVARISTO, 2011, p. 32). Não posso deixar de destacar que a hegemonia do texto escrito na Academia ainda perdura, inclusive, para deslegitimar outras culturas que não tenham adotado essa hegemonia ocidental (desde o século $V$ a. C. com a ascensão do pensamento racional na Grécia Antiga). A cultura afro-brasileira foi, e ainda é, oral, passada pelos mais velhos, pelos ancestrais divinizados e sua passagem para a escrita, como forma de não esquecer, tem se tornado prática comum. Mas será mesmo que escrever os ítans, ou seja, torná-los registros, é uma forma de preservá-los? Sobre essa questão da escrita e da memória discorremos sobre ela desde Platão (428 a.C.-348 a.C.) com Fedro (370 a.C.) e ainda não chegamos a nenhum consenso. Mas, Evaristo (2011) vai afirmar que, em relação aos contos de Mãe Beata, ela é: "Detentora de uma cultura oralizada, reconhece que o texto escrito é um meio de preservá-la e difundi-la. Distingue a importância e a urgência de traduzir sua voz em letra, em escrita." (EVARISTO, 2011, p. 33). Não há, assim, outra maneira de "traduzir" a oralidade dos contos que não através da oralitura, contos que mesmo lidos exigem do leitor uma "corporeidade", surgindo, quase sempre, nas experiências de leitura a figura uma gritot.

Heloisa Toller Gomes (2004), em seu artigo: "Visíveis e invisíveis grades: vozes de mulheres na escrita afro-descendente contemporânea", afirma que: "A escrita (da mulher) negra é construtora de pontes. Entre o passado e o presente, pois tem traduzido, atualizado e transmutado em produção cultural o saber e a experiência de mulheres através das gerações" (GOMES, 2004, p. 13). Essas pontes se erguem, principalmente, no resgate de reminiscências de memórias individuais que buscam recompor uma memória coletiva, mais do que tudo, retaliada, dilacerada. Sendo assim, Mãe Beata de Yemonjá constrói pontes e reatualiza os ítans mesclando-os com o presente, ou melhor, os retrata dentro de um tempo mítico. Exu, o menino do caroço do dendê, mais conhecido como o mensageiro entre os Orixás e os humanos é quem "recolhe" essas histórias. Acima de tudo, os contos dialogam com uma literatura de autoria feminina negra, doravante literatura afrofeminina (SANTIAGO, 2012) em uma escrita em que o corpo está presente, corpo político, social, histórico que resistiu e resiste.

No universo literário afro-brasileiro, o narrar, seja ele ficcional ou poético, é inseparável da dinâmica espaço-tempo a qual incorpora o corpo na opacidade de seu silêncio. Além desse corpo calado, em sua resistência obstinada e capacidade de sobrevivência, a literatura trabalha o corpo vitimado pela crueldade e privação. (GOMES, 2007, p. 11). 
Gomes (2007) vai perceber a presença desse corpo na literatura negra-brasileira (CUTI, 2017), corpo esse que, como a memória, está dilacerada, trazendo as marcas da escravização colonial e da sua consequente escravização atual ancorada no racismo estruturado e institucionalizado. Esse narrar, advindo de uma cultura oralizada, exige o uso desse corpo, para que essa voz tanto tempo silenciada saia com força e reverbere no mundo. Assim, a fala, o sopro é axé, é força vital. Nas lendas de criação do ser humano na mitologia afro-brasileiro temos a figura de Oxalá que molda do barro de Nanã os corpos humanos. Por fim, ele sopra os fluídos nesses corpos. Nos terreiros de Candomblé, Batuque no Rio Grande do Sul e outros cultos aos Orixás, canta-se em yorubá, por vezes em nagô, chamando esses cantos de "rezas", maneira de manter viva a cultura em suas raízes. Sendo assim, Leda Martins (2003) observa esses rituais de descendência africana, em especial a congada, no Brasil e percebe como o "corpo" é elemento constitutivo elementar.

No âmbito dos rituais afro-brasileiros, a palavra poética, cantada e vocaliza, ressoa como efeito de uma linguagem pulsional e mimética do corpo, inscrevendo o sujeito emissor, que a porta, e o receptor, a quem também circunscreve, em um determinado circuito de expressão, potência e poder. (MARTINS, 2003, p. 67).

Esses rituais portam a cultura ancestral de cada nação africana, reunindo em uma só a que chamamos de afro-brasileira, advindas de África, mas que se desenvolvem no Brasil. Esse circuito da palavra poética, seja pela contação de história dos griots ou dentro de famílias religiosas, portam o fluído vital: o axé. Quem conta o ítan reatualiza as lendas heroicas de seus ancestrais e, também, porta nesse momento ritual a potência, pois resgata uma memória ancestral e, talvez, milenar e a propaga no tempo, momento em que é rompido o espaço-tempo ocorrendo o retorno a um tempo mítico ainda presente no Ori de cada um. Essa potência de voz, de corpo e memória propagados no tempo retornam e portam em si, o poder.

Esse poder, que emana a resistência que sempre existiu em solo brasileiro desde a chegada dos povos africanos escravizados, diferente do que é propagado na História Oficial, é advindo, sobretudo, da Ancestralidade (com A maiúsculo). Retomar os ítans não é um simples ato de contar histórias, de regressar a um tempo primordial ou mesmo de passar conhecimento aos mais novos, retomar os ítans é reforçar esse poder, é religar-se às raízes, é (r) existir. Esse poder dos ítans não está individualizado ou centralizado na figura de quem o conta, apesar de falar de Orixás (Donos do Ori, do topo da cabeça, do chacra coronário), os ítans pertencem à memória coletiva e são, assim, uma prática também coletiva. Logo, a Ancestralidade, que norteia esse trabalho, como afirma Laura Cavalcante Padilha (1997):

[...] constitui a essência de uma visão que os teóricos das culturas africanas chamam de visão negra-africana do mundo. Tal força faz com que os vivos, os mortos, o natural e o sobrenatural, os elementos cósmicos e os sociais 
interajam, formando eles de uma mesma e indissolúvel cadeia significativa. (PADILHA, 1997, p. 10).

Nessa esteira de afrocentrismo, buscamos, então, o conceito de oralitura defendido e cunhado por Leda Martins para pensarmos a escrita de mulheres negras, em especial, os contos de Mãe Beata de Yemonjá. Acerca de Ancestralidade elencamos as lyá Mi Oxorongás, figuras mítico-religiosas que aglutinam em si o poder feminino das mães ancestrais. As lyá Mi Oxorongás são temidas por representarem esse poder feminino, pois, não podemos esquecer que, apesar da raiz africana, a cultura africana se mescla com a cultura judaico-cristã e a demonização do poder feminino é imposto a essas figuras míticas. As lyá Mi Oxorongás detêm o poder de dar a vida, regem a maternidade, a fecundidade e a fartura, mas, detêm o poder da morte, da pobreza, das secas que geram infecundidade e o mais temido na cultura: infertilidade. Não podemos esquecer que alguém sem descendência não se torna ancestral, afinal, é função da família os ritos fúnebres (como o axexé) na cultura africana, afro-brasileira e ocidental desde a Grécia Antiga. Buscando uma possível definição para o termo, Leda Martins (1997) afirma que:

[...] oralitura, matizando na noção deste termo a singular inscrição cultural que, como letra (littera), cliva a enunciação do sujeito e de sua coletividade, sublinhando ainda no termo do seu valor de litura, rasura da linguagem, alteração significante, constitutiva da alteridade dos sujeitos, das culturas e de suas representações simbólicas. (MARTINS, 1997, p. 21).

O conceito se baseia na dupla injunção dos sujeitos envolvidos, seja aquele que conta utilizando seu corpo, sua voz, sua memória, seja aquele que ouve, acessando a memória ancestral, as marcas corporais e recebendo o axé da voz propagada do gritot (ou contador). Essa subjetividade é posta em suspensão para que a coletividade do ato ritual, que opera na ruptura do espaço-tempo, transmita esse poder, esse axé aos envolvidos. Ainda, Martins questiona a "litura" a letra como rasura da linguagem, fenda aberta que permite que esse contato e esse espaço ritualizado se propague. Assim: "[...] os significantes voz, corpo e memória são os atavios que tecem o corpo alterno e alternativo dessa escritura. Ali [...] reinaugura, em cada pulsação rítmica, em cada expressão figurada, em cada gesto textual, as sete faces dessas silhuetas desdobráveis." (MARTINS, 2007, p. 65).

Não é de hoje que as mulheres negras são duplamente (ou mais) silenciadas, questões de gênero e raça perpassam essa opressão e, também, atravessam a escrita dessas mulheres e sua (auto) representação. Se os autores homens, inclusive negros, as representam sob os dois mitos antagônicos cristãos: Maria Mater e Lilith, essas representações se desdobram no corpo desejado, sexualizado e erotizado da mulata, com forte influência midiática, e o corpo marginalizado da empregada doméstico. Em certas representações a mulata e a doméstica se unem, apresentando a iniciação sexual dos filhos dos (novos) Senhores. Essas mulheres são, então, objetos de representação literária e essa representação contribui para seu silenciamento. Ao se falar das mulheres negras, nega-se a elas o espaço de fala, isso ocorre, comumente nos trabalhos acadêmicos em 
que pesquisadores se colocam no espaço de "salvadores" dessa literatura, afirmando serem eles quem "resgataram" essas autoras. Contudo, a análise dessas obras perpassa, principalmente (para não afirmar que "somente") críticos europeus, deixando de lado toda uma cultura.

Sendo assim, a prof. Dra. Ana Rita Santiago (2012), elaborando uma cartografia das escritoras negras baianas, retoma como pilares da literatura afrofeminina Maria Firmina dos Reis (1822-1917); Antonieta de Barros (1901-1952); e Carolina Maria de Jesus (19141977); três mulheres negras que representam seus pares, de diferentes perspectivas, tematizam sobre o gênero e a raça e, por que não, testemunham o genocídio dos povos afro-diaspóricos ainda em voga pelo racismo. Essas escritoras rompem com a insistente "mão" ou a "máscara de flandres" que as cala, resistindo a opressão e se autorrepresentando, buscando a memória coletiva dilacerada. Reafirmando as palavras de Gomes (2004), a escrita dessas mulheres negras é construtora de pontes.

\begin{abstract}
Nesse contexto, a literatura afrofeminina é uma produção de autoria de mulheres negras que se constitui por temas femininos e de feminismo negro comprometidos com estratégias políticas civilizatórias e de alteridades, circunscrevendo narrações de negritudes femininas/ feminismos por elementos e segmentos de memórias ancestrais, de tradições e culturas africano-brasileiras, do passado histórico e de experiências vividas, positiva e negativamente, como mulheres negras. Em um movimento de reversão, elas escrevem para (des) silenciarem as suas vozes autorais e para, através da escrita, inventarem novos perfis de mulheres, sem a prevalência do imaginário e das formações discursivas do poder masculino, mas com poder de fala e de decisão, logo senhoras de si mesmas. (SANTIAGO, 2012, p. 155).
\end{abstract}

Esse movimento de reversão a que Ana Rita Santiago (2012) se refere transmuta o que Leda Martins (1997; 2003; 2007) compreende e cunha de oralitura, uma literatura que nasce das marcas corporais e que nasce, também, do corpo. "A literatura afrofeminina, neste sentido, pode ser considerada como um processo contínuo de (re) invenções de memórias, histórias e narrações sobre identidades, femininos e feminismos negros." (SANTIAGO, 2012, p. 163) Essas reinvenções corroboram para um resgate de memória ancestral coletiva.

\title{
Vamos aos contos: griotizando
}

No conto "O cachimbo da Tia Cilu", Mãe Beata (2008) conta a história de uma Ancestral, divinizada pelo ritual fúnebre afro-brasileiro, o axexé. Juana Elbein dos Santos (1986), em Os nagô e a morte, discorre sobre os rituais fúnebres dos nagôs, em especial, e da cultura afro-brasileira de forma mais geral afirmando que: "Morrer é uma mudança de estado, de plano de existência e de status" (SANTOS, 1986, p. 221), status porque quem morre, passando pelo ritual de axéxé ou, àsèsè na grafia elencada por Santos (1986), tornase um Ancestral que pode ser acessado e é cultuado como Egun ou Babá Egun. "Sem àsèsè, não há começo, não há existência. O àsèsè é a origem e, ao mesmo tempo, o morto, 
a passagem da existência individual ao àiyé à existência genérica do órun." (SANTOS, 1986, p. 235).

Enquanto temos, de um lado, a visão ocidental judaico-cristã da morte em que marca o fim de uma vida em que o que sobram, às vezes, são apenas as lembranças dos patriarcas, temos de um lado um culto à memória desses Ancestrais que são alimentados periodicamente com ebós. Outra ruptura encontra-se no ritual fúnebre em que de um lado temos um corpo enterrado e esquecido em que o enterro é o fim de todo ritual, para os afrodiaspóricos o enterro é apenas o começo do ritual que, dependendo do cargo do Egun, pode durar 7, 14 ou 21 dias.

Mãe Beata (2008) apresenta Tia Cilu como: "[...] uma velha muito bondosa, que jogava búzios e rezava todas as crianças do lugar" (BEATA DE YEMONJÁ, 2008, p. 31), sendo assim, uma ialorixá iniciada no culto aos Orixás e que já cumprira com boa parte dos rituais de iniciação, pois, joga o oráculo de Ifá. Os búzios são um dos últimos axés a serem passados aos iniciados pelas mãos do sacerdote iniciado, pois exige conhecimento e vivência, além disso, há Orixás que mesmo seu sacerdote estando pronto não o liberam. No conto, há a presença de outros dois personagens: Uma senhora e seu filho mascate. Ao que nos indica a narrativa, esse filho mascate conhecera tia Cilu ainda menino o que nos permite pensar que, além de bondosa e candomblecista, tia Cilu também desempenhara o papel de parteira da região.

O mascate, devido à profissão, viajava bastante e em um dos seus retornos encontra Tia Cilu sentada no beiral da casa pitando um cachimbo. Como de costume lhe toma a bênção a que Tia Cilu responde: "Bênção de Deus meu filho. Deus te ponha virtude." (BEATA DE YEMONJÁ, 2008, p. 31). O mascate, então, segue seu caminho em direção a sua casa, estranhando ver Tia Cilu na chuva pitando seu cachimbo. Interessante notarmos que a principal Orixá do axéxé, após Exu, é lansã/Oyá, cujos domínios são os mortos e sua representação na natureza são os raios e relâmpagos. Sendo assim, o elemento que pode passar despercebido é, na verdade, elemento de construção básico para o fechamento do conto e da passagem do conhecimento aos iniciados.

Chegando a casa, o menino encontra sua mãe muito triste, chorando e estranha a falta de recepção materna, visto que ele só retornava após vender todos os seus produtos. Nesse meio tempo, ele reflete que estranho as manias das pessoas mais velhas: "Esta hora Tia Cilu sentada aí na beirada da casa pitando seu cachimbo" (BEATA DE YEMONJÁ, 2008, p. 31) ao que a mãe dá um pulo e fala ser impossível, pois naquele dia completavase o último dia do axèxè de Tia Cilu. Mãe Beata (2008) encerra o conto com uma espécie de moral, como aquelas descritas nos contos de Charles Perrault (1628-1703) em que o conto é resumido e refletido: "Este conto mostra uma verdade: para nós, iniciados, não existe a morte. Somos ancestrais, e Tia Cilu era uma ancestral” (BEATA DE YEMONJÁ, 2008, p. 32).

Esse conto não vai apresentar diretamente as lyá Mis, as mães que viram pássaro, mas elas estão presentes no conto. Afinal, as duas mães tem em seus oris as Orixás que 
representam o antigo culto. Ao passar pelo axéxé, tia Cilu tem passagem para conhecer sua Ancestralidade e, como mãe, a possibilidade de retornar como pássaro. A presença de tia Cilú se dá, apenas, por ter sido o último dia de seu ritual mortuário, em que lhe são servidas suas comidas preferidas ao lado dos Orixás que representam a boa morte e a boa passagem.

O segundo conto comtemplado no recorte deste trabalho é "lyá Mi, a mãe ancestral". O conto começa com a descrição de que em algum lugar, sem marcas deste espaço, logo, mítico e antigamente, marcando que a história a ser contada remonta da Ancestralidade, que vivia uma senhora muito velha e que ficara grávida de um menino, mas que, infelizmente acaba morrendo no parto, indo, então ao Orum. "Contam muitos casos de lyá Mi como má, mas em tudo existe o mal e o bem." (BEATA DE YEMONJÁ, 2008, p. 41). As lyá Mi Oxorongás são um culto de matriz africana que marca a força da mulher em que essas Orixás detêm o poder da vida e, atrelado a ele, o poder da morte (lku). Reginaldo Prandi resgata esses ítans, mas como o conheço de minha vivência nos quilombos culturais não o cito, não é preciso que um branco fale para que o discurso ancestral seja legitimado, mas destaco que ele tem um trabalho que resgata esse e vários outros ítans. Os ítans dedicados as lyá Mi Oxorongás, no Brasil, se mesclam com a figura da bruxa europeia e acabam perdendo, em muito, a força que tem em África, mas, resistem e todas as mulheres tem uma fase de suas vidas mensais em que se aproximam dessas mães ou dessa energia natural: na menstruação. Assim, nos candomblés e outros cultos de matriz africana, as mulheres menstruadas são interditadas de participarem dos rituais, há " $n$ " explicações que partem, quase sempre, de uma visão machista e eurocêntrica, que parte de pecado e impureza. Na verdade essas mulheres menstruadas estão ligadas diretamente às lyá Mis portando em seus ventres a morte e o renascimento do poder, do axé da vida, e assim, em respeito à essa natureza os Orixás não se manifestam e, em respeito aos Orixás, essas mulheres entram em repouso e não participam das festas e rituais, não por interdição.

Essa mulher então fica muito triste com a ruptura, com o afastamento abrupto de seu filho e chora dia e noite, então, as Mães Ancestrais que não são nem boas nem más, porque essa é uma visão eurocêntrica, chamam a esta mulher e lhe dizem.

Olha, nós aqui, quando saímos do mundo, chegamos aqui e temos de esquecer tudo. Mas como você está assim, triste com o seu filho, eu vou the fazer virar uma coruja e você vai se assentar na cumeeira da casa que foi sua e ficar esperando. Quando não tiver ninguém no quarto, você se vira em uma mulher e amamenta seu filho. Isto acontecerá todos os dias até que ele fique forte e mais criado. (BEATA DE YEMONJÁ, 2008, p. 41).

E assim ocorre, a coruja fica na cumeeira da casa aguardando os momentos certos para amamentar seu filho. É importante sempre salientar que o conto não apresenta nada de "fantástico", afinal, essa visão é orientada por uma gama de teóricos europeus, em especial russos, e o conto de Mãe Beata de Yemonjá (2008) gira em torno da cultura afrobrasileira e não há nada de fantástico em transformar-se em pássaro, pois essa divindade da natureza é representada por esse animal mítico, em especial, as corujas. Mãe Beata 
encerra o conto com: "Só em casos de grandes necessidades é que elas vêm aqui" (BEATA DE YEMONJÁ, 2008, p. 41), afinal essas Orixás pertencem a natureza e aos ciclos que essa natureza demanda como, por exemplo, as secas e as enchentes. Essas mães Ancestrais demarcam mais um grupo de Orixás que representam o poder feminino das mulheres que conduzem os (atuais) quilombos culturais resgatando e mantendo um matriarcado que vem desde África e não é nenhuma outra invenção eurocêntrica ou novidade de cunho feminista.

O terceiro e último conto contemplado pelo recorte é uma homenagem que Mãe Beata de Yemonjá (2008) faz a sua mãe, a Tia Afalá e a ela mesma e intitula-se "Conto dedicado à minha mãe, do Carmo". A cena que é contada é o nascimento de Mãe Beata, filha de Yemonjá e Exu e que, assim que nasce, Tia Afalá resolve colocar algumas folhas na sua cabeça, que é o primeiro ritual no Candomblé e, também, outras religiões como, por exemplo, a unção do batismo. Mãe Beata nos conta que sua mãe já tivera outros vinte e cinco filhos e que, mesmo assim, assustava a todos pelo tamanho.

Um dia, do Carmo teve muita vontade de comer peixe. Ela pegou o jereré e foi pescar no rio que passava por dentro do engenho. Quando ela estava pescando, a bolsa d'água se rompeu. Ela saiu da água e, quando ia atravessando a estrada, eu nasci, ali mesmo. Uma menina. Chamaram Tia Afalá, que me carregou e à minha mãe para casa, para cortar o umbigo. Tia Afalá viu que era uma menina muito forte, mas que a tinha a cabeça ainda mole. (BEATA DE YEMONJÁ, 2008, p. 121).

Neste conto percebemos a presença de duas Ancestrais de Mãe Beata, mulheres que marcaram sua vida que são sua Mãe, do Carmo, e a figura da parteira de Engenho de Dentro, Tia Afalá, figura importante que identifica os Orixás que caminharão ao lado da menina que acabara de nascer em uma encruzilhada. Para as religiões de matriz africana, o fim de toda iniciação é quando o iniciado torna-se um Ancestral, cultuado e cuidado na casa de santo no culto à Egungun e, Mãe Beata encerra seu conto: "Hoje, sou uma omorixá e uma lutadora de minha religião e de minha raça. Meu nome: Beata de Yemonjá." (BEATA DE YEMONJÁ, 2008, p. 122), na verdade, hoje ela é uma Ancestral, ao lado de Tia Afalá, de sua Mãe do Carmo, ao lado de Tia Cilu, de Mãe Menininha de Oxum e de outras mulheres e homens negros que, em vida, cultuaram aos seus Orixás e não permitiram que o pedaço de África cravado no peito fosse perdido ou esquecido.

Por ora, concluo o presente trabalho que teve como objetivo afrocentrar a teoria utilizando teóricas negras com a presença de apenas um homem negro: Cuti (2017) que nos vale para descentralizar o questionamento e uso dos termos usados pela Academia (eurocentrada) de literatura afro-brasileira. Cuti questiona quem tem medo do negro e nos remete a obra recente de Djamila Ribeiro (1980- ), Quem tem medo do feminismo negro? (2018).

A cultura afro-brasileira tem sobrevivido há anos de opressão e discriminação, nosso culto já foi proibido, nossa cultura ainda é vista como menor em relação à Europa e mesmo assim resistimos através da oralidade. Se, há mais de cinco séculos a cultura oral manteve 
viva nossa Ancestral cultura enraizadamente africana, não é a mudança que a modernidade empurra às sociedades de massa, hegemonicamente visual, que vai apagar ou desprestigiar a cultura afro-brasileira. Não precisamos escrever em livros os ítans dos Orixás, nem os fundamentos religiosos, até porque vários antropólogos brancos já o fizeram tentando vestir suas "capas de herói". Resistimos sem eles e, com a força das mulheres negras que mantêm o matriarcado vamos continuar resistindo.

\section{Referências}

ALVES, Juliana Franco. Tempos de griotizar a letra: Em busca de uma poética da voz afrobrasileira em Caroço de dendê, de Mãe Beata de Yemonjá. 2012. 143f. Dissertação (Mestrado em Letras) - Programa de Pós-graduação em Letras, Universidade Estadual de Londrina, Londrina, 2012.

BEATA DE YEMONJÁ, Mãe. Caroço de dendê: a sabedoria dos terreiros: como lalorixás e Babalorixás passam conhecimentos a seus filhos. 2. ed. Rio de Janeiro: Pallas, 2008.

CUTI, Luiz Silva. Quem tem medo da palavra negro. Disponível em: http://www.sedes.org.br/Departamentos/Psicanalise/pdf/quemtemmedodapalavranegro_cu ti.pdf. Acesso em: 20 abr. 2017.

EVARISTO, Conceição. Mãe Beata de Yemonjá. In: DUARTE, Eduardo de Assis. Literatura e afrodescendência no Brasil: antologia crítica. Belo Horizonte: Ed. UFMG, 2011.

GOMES, Heloisa Toller. Visíveis e invisíveis grades: vozes de mulheres na escrita afrodescendente contemporânea. Caderno Espaço Feminino, Uberlândia, v. 12, n. 15, p. 1326, 2004.

GOMES, Heloisa Toller. Heranças díspares na formação de um espaço discursivo: a literatura afro-brasileira. In: SECCO, Carmen; SALGADO, Maria Teresa; JORGE, Silvio (Orgs.) Anais do III Encontro de professores de literaturas africanas, 2007, Rio de Janeiro. Rio de Janeiro: L. Christiano Editorial, 2007, p. 1-13.

MARTINS, Leda. Afrografias da memória. São Paulo: Perspectiva; Belo Horizonte: Mazza Edições, 1997.

MARTINS, Leda. Performances da oralitura: corpo, lugar de memória. Letras, Santa Maria, n. 26, p. 63-81, 2003.

MARTINS, Leda. A fina lâmina da palavra. O eixo e a roda, Belo Horizonte, v. 15, p. 55-84, 2007.

PADILHA, Laura Cavalcante. Entre voz e letra: o lugar da ancestralidade na ficção angolana do século XX. Niterói: Ed. UFF, 1997.

RIBEIRO, Djamila. Quem tem medo do feminismo negro?. São Paulo: Companhia das letras, 2018.

RODRIGUES, Felipe Fanuel Xavier. De Stamps ao Recôncavo: encruzilhada de narrativas afrodescendentes traduzidas em literatura contemporânea. 2016. 268f. Tese (Doutorado 
em Letras) - Instituto de Letras, Universidade do Estado do Rio de Janeiro, Rio de Janeiro, 2016.

SANTIAGO, Ana Rita. Vozes literárias de escritoras negras. Cruz das Almas: Ed. UFRB, 2012.

SANTOS, Juana Elbein dos. Os nàgô e a morte: Pàde, Asèsè e o culto Égun na Bahia. Petrópolis: Vozes, 1986.

SILVA, Glória Cecília de Souza. Os "fios de contos" de mãe Beata de Yemonjá: mitologia afro-brasileira e educação. 2008. 139f. Dissertação (Mestrado em educação) - Faculdade de Educação, Universidade do Estado do Rio de Janeiro, Rio de Janeiro, 2008.

\section{NOTAS DE AUTORIA}

Dênis Moura de Quadros (denisdpbg10@gmail.com) é doutorando em Letras - área de concentração História da Literatura - pela Universidade Federal do Rio Grande - FURG, além de ser mestre em Letras, área de concentração História da Literatura, pela mesma Universidade, onde pesquisa sobre Literatura Brasileira; Luto sob as diversas perspectivas psicológicas e psiquiatras; o negro na Literatura Brasileira; a Literatura produzida por mulheres e Literatura Afrofeminina. Bolsista CAPES/DS.

\section{Como citar esse artigo de acordo com as normas da ABNT}

QUADROS, Dênis Moura de. Oralitura e figura mitológica de lyá Mi Oxorongá em "Caroço de dendê", de Mãe Beata de Yemonjá. Anuário de Literatura, Florianópolis, v. 26, p. 01-12, 2021.

\section{Contribuição de autoria}

Não se aplica.

\section{Financiamento}

O presente trabalho foi realizado com apoio da Coordenação de Aperfeiçoamento de Pessoal de Nível Superior - Brasil (CAPES) - Código de Financiamento 001.

\section{Consentimento de uso de imagem}

Não se aplica.

\section{Aprovação de comitê de ética em pesquisa}

Não se aplica.

\section{Conflito de interesses}

Não se aplica.

\section{Licença de uso}

Os/as autores/as cedem à Revista Anuário de Literatura os direitos exclusivos de primeira publicação, com o trabalho simultaneamente licenciado sob a Licença Creative Commons Attribution (CC BY) 4.0 International. Estra licença permite que terceiros remixem, adaptem e criem a partir do trabalho publicado, atribuindo 0 devido crédito de autoria e publicação inicial neste periódico. Os autores têm autorização para assumir contratos adicionais separadamente, para distribuição não exclusiva da versão do trabalho publicada neste periódico (ex.: publicar em repositório institucional, em site pessoal, publicar uma tradução, ou como capítulo de livro), com reconhecimento de autoria e publicação inicial neste periódico.

\section{Publisher}

Universidade Federal de Santa Catarina. Programa de Pós-graduação em Literatura. Publicação no Portal de Periódicos UFSC. As ideias expressadas neste artigo são de responsabilidade de seus/suas autores/as, não representando, necessariamente, a opinião dos/as editores/as ou da universidade.

\section{Histórico}

Recebido em: 05/04/2020 
Aprovado em: $25 / 05 / 2020$

Publicado em: 23/02/2021 